Southern Illinois University Edwardsville

SPARK

Pharmacy Faculty Research, Scholarship, and Creative Activity

School of Pharmacy

$1-2011$

\title{
Current Therapies for Chronic Hepatitis C
}

McKenzie C. Ferguson

Southern Illinois University Edwardsville, mcfergu@siue.edu

Follow this and additional works at: https://spark.siue.edu/pharmacy_fac

Part of the Pharmacy and Pharmaceutical Sciences Commons

\section{Recommended Citation}

Ferguson, McKenzie C., "Current Therapies for Chronic Hepatitis C" (2011). Pharmacy Faculty Research, Scholarship, and Creative Activity. 4.

https://spark.siue.edu/pharmacy_fac/4

This Article is brought to you for free and open access by the School of Pharmacy at SPARK. It has been accepted for inclusion in Pharmacy Faculty Research, Scholarship, and Creative Activity by an authorized administrator of SPARK. For more information, please contact magrase@siue.edu,tdvorak@siue.edu. 


\title{
Review of Chronic Hepatitis C \& Current Therapies
}

\author{
Reviews of Therapeutics
}

Pharmacotherapy

\section{McKenzie C. Ferguson, Pharm.D., BCPS}

From the School of Pharmacy, Southern Illinois University Edwardsville, Department of Pharmacy Practice, Edwardsville, Illinois.

Address for reprint requests:

Southern Illinois University Edwardsville

School of Pharmacy

220 University Park Drive, Ste 1037

Edwardsville, IL 62026-2000

Email: $\underline{\text { mcfergu@ } @ \text { siue.edu }}$

Keywords: hepatitis $\mathrm{C}, \mathrm{HCV}$, ribavirin, interferon, peginterferon alfa-2a, peginterferon alfa-2b, albinterferon, taribavirin, telaprevir, therapeutic efficacy, safety

The author received no sources of support in the form of grants, equipment, or drugs. 


\begin{abstract}
Hepatitis $\mathrm{C}$ virus affects more than 180 million people worldwide and as many as 4 million people in the United States. Given that most patients are asymptomatic until late in disease progression, diagnostic screening and evaluation of patients that display high-risk behaviors associated with acquisition of hepatitis $\mathrm{C}$ should be performed. Chronic hepatitis $\mathrm{C}$ is associated with cirrhosis, hepatic failure and death, therefore treatment is aimed at reducing these complications as well as improving quality of life and minimizing adverse effects. The American Association for the Study of Liver Diseases Practice Guidelines on the Diagnosis, Management and Treatment of Hepatitis $C$ represent the gold standard for guidance on the management of hepatitis $\mathrm{C}$. Standard treatment for hepatitis $\mathrm{C}$ is peginterferon alfa in combination with ribavirin. Currently, two pegylated interferon products are approved by the U.S. Food and Drug Administration for the treatment of hepatitis $\mathrm{C}$. The duration of therapy with peginterferon and ribavirin is currently dictated by viral genotype and virologic response. Additional therapies are currently under investigation for treatment of chronic hepatitis $\mathrm{C}$ and show early promise of comparative efficacy and reduced adverse effects. Special considerations in certain populations, including co-infection with human immunodeficiency virus, end-stage renal disease, injection drug use, pregnancy and pediatric patients should guide treatment decisions.
\end{abstract}




\section{Introduction}

\section{Epidemiology}

Hepatitis $\mathrm{C}$ virus (HCV), a single-stranded RNA virus, is the most common chronic bloodborne illness in the United States. It is estimated that as many as 4 million people are chronically infected. Though reported surveillance data likely reflect accurate trends, it also likely underestimates the true burden of disease. ${ }^{1} \mathrm{HCV}$ was officially recognized in 1989 and had previously been referred to as "non-A, non-B hepatitis.", The majority of patients who develop acute hepatitis $\mathrm{C}$ will develop chronic infection and as many as $30 \%$ of chronic HCV infections are from unknown causes. ${ }^{3}$

The incidence rates of acute hepatitis $\mathrm{C}$ have declined since the 1980s and 1990s and have steadied since 2003, possibly as a result of increased education and public awareness of transmissible risk factors (Figure 1). ${ }^{1,4-5}$ Routine blood screening, implemented in 1992, has also contributed to the declining incidence. HCV rates in people aged 25-39 years, typically those with the highest rates of infection, have decreased 90\% from 1990 to 2007. Additionally, the historically higher incidence in males is declining, with similar rates now reported in both sexes. Currently, the prevalence of chronic infection is highest in persons aged 40-49 years. Rates during 2004-2007 were similar among racial/ethnic groups except for American Indians/Alaskan Natives, in which incidence rates increased. Previous prevalence data showed higher rates in non-Hispanic blacks. ${ }^{1}$

\section{Complications \& Economic Burden}

Given that the majority of patients living with chronic hepatitis $\mathrm{C}$ are relatively young and often asymptomatic, the future economic impact of associated complications is likely to be substantial. Cirrhosis, liver failure and hepatocellular carcinoma are possible complications of chronic HCV. As many as $20-30 \%$ of patients with chronic HCV will progress to cirrhosis within 20 years. Chronic viral hepatitis is a leading cause of hepatocellular carcinoma and one of the most common reasons for liver transplantation in the U.S. ${ }^{1}$ It is estimated that 12,000 deaths annually are a result of chronic liver disease due to hepatitis $\mathrm{C}$ infection. ${ }^{5}$

One group of authors analyzed U.S. hospitalizations and prescription data over an 8 year period (1994-2001) to understand outcomes associated with hepatitis C. Hospitalization trends were analyzed using the Nationwide Inpatient Sample from the Healthcare Cost and Utilization Project where a $20 \%$ stratified sample of U.S. community hospitals was collected for data extrapolation. Outpatient data was obtained via the National Ambulatory Medical Care Survey and prescription data from Verispan Source Prescription Audit. ICD-9 codes were used for diagnoses. Though the average length of stay for liver-related hospitalizations associated with HCV decreased from 8.5 in 1994 to 6.9 in 2001, the number of hospitalizations more than doubled (111 vs. 244, respectively). Additional findings included that for every $\$ 100,000$ spent in nationwide hospitalizations in 2001, \$427 were due to liver-related complications from 
hepatitis C, compared with $\$ 145$ in 1994 . Patients aged 40-49 accounted for more hospitalizations, greater expenditures and had a higher incidence of death than other age groups. Physician office visits by HCV patients and prescription drug expenditures also greatly increased. ${ }^{6}$

\section{Diagnosis}

The American Association for the Study of Liver Diseases (AASLD) Practice Guidelines on the Diagnosis, Management and Treatment of Hepatitis $C$ represent the gold standard for guidance on the management of hepatitis C (Table 1). ${ }^{7}$ These guidelines were approved and are supported by the AASLD, the Infectious Disease Society of America, and the American College of Gastroenterology. ${ }^{7}$

A laboratory diagnosis of $\mathrm{HCV}$ is determined after screening for possible risk factors and evaluation of signs and symptoms. Acute illness presents symptomatically in 20-30\% of patients. Many patients chronically infected with HCV are asymptomatic or may exhibit only mild symptoms. ${ }^{8}$ Possible symptoms include abdominal pain, fever, fatigue, loss of appetite, nausea and vomiting. ${ }^{3,8-9}$

\section{Risk Factors}

HCV infection is transmitted by exposure to infected blood or blood products (Table 2). ${ }^{1-3,7,9-10}$ Injection drug use (IDU) is the most common route of exposure to hepatitis $\mathrm{C}^{1,7}$ All persons who report illicit drug use, including intranasal cocaine use should be screened for $\mathrm{HCV}^{2,7}$ The prevalence of HCV reported in injection drug users is extremely high, with a proportional relationship to the length of drug use. Within 5 years of beginning injection drug use, 1 in 3 persons will become infected with $\mathrm{HCV} .{ }^{11}$

Other populations at risk of HCV infection include individuals who received a blood or blood component transfusion prior to 1992, healthcare exposure, patients who ever received chronic hemodialysis, persons with human immunodeficiency virus (HIV), children of HCV-infected mothers, and persons with multiple sexual partners, although transmission between monogamous partners is uncommon (see Table 2). ${ }^{1-3,7,9-10}$ The risk of HCV transmission between monogamous sexual partners is less than $1 \%{ }^{3}$ Persons who have ever been on chronic hemodialysis, those with unexplained abnormal aminotransferase levels or infected with HIV are considered at risk due to the higher prevalence of infection in these patients. ${ }^{7}$ Less than $5 \%$ of infants born to HCVinfected mothers will acquire the infection. ${ }^{3}$ Additionally, breastfeeding has not been linked to transmission of $\mathrm{HCV} .{ }^{3,7}$ Though exposure via tattooing, acupuncture and body piercing is possible, each has rarely been reported as the sole possible mode of transmission. ${ }^{2-3,7,9}$

Several risk factors are associated with progression to chronic disease. Nonmodifiable risk factors include increased age at the time of initial infection, male gender, race and genetic factors linked to polymorphisms of specific genes involved in the rate of fibrosis and hepatocellular 
carcinoma. Though African-American patients display a higher rate of development of hepatocellular carcinoma, a lower response to therapy and higher liver-related mortality as compared to whites, studies have shown they are actually less likely to progress to cirrhosis. Limited evidence shows that Latino patients, on the other hand, progress faster to cirrhosis compared to whites. Potentially modifiable risk factors include alanine aminotransferase levels (ALT), alcohol intake, smoking, and co-infection with HIV or hepatitis B virus (HBV). ${ }^{10}$

Clinical features of disease progression to cirrhosis may include jaundice, enlarged liver and/or spleen, muscle wasting and ascites. Elevated alkaline phosphatase, gamma glutamyl transpeptidase and aspartate aminotransferase (AST) may also be seen. Low platelet and white blood cells may also be observed. Extrahepatic manifestations are uncommon but can include cryoglobulinemia, glomerulonephritis and porphyria cutanea tarda. ${ }^{3}$

The diagnosis of chronic HCV is established when anti-HCV is present and serum aminotransferase levels remain elevated for $\geq 6$ months. ${ }^{3,7}$ Polymerase chain reaction (PCR) testing for HCV RNA will establish the diagnosis and is indicative of current and active infection.

\section{Laboratory Testing}

Both qualitative and quantitative tests are utilized in the diagnosis of HCV. Anti-HCV confirmed by enzyme immunoassay (EIA) is the initial serologic test used to establish exposure to HCV but is not necessarily indicative of current infection. The current EIAs available have specificity greater than $99 \%$. Current infection can be established with quantitative analysis of HCV RNA via PCR or transcription-mediated amplification. Currently available PCR assays have excellent specificity (98 to 99\%) and will detect HCV RNA in the serum to a lower limit of 50 to 100 copies/milliliter (mL). Most patients with chronic HCV will have levels of HCV RNA (viral load) between $100000\left(10^{5}\right)$ and $10000000\left(10^{7}\right)$ copies per $\mathrm{mL}$ (or 50000 to 5 million international units $[\mathrm{IU}] / \mathrm{mL})$. Laboratory interpretation of anti-HCV and HCV RNA for diagnosis is described in Table 3.,

Confirmatory testing is essential in high risk patients testing negative for anti-HCV. Immunocompromised patients, including those with HIV, solid organ transplant recipients or those receiving hemodialysis, may test as false-negative due to the inability to mount a sufficient immune response. Likewise, persons with acute $\mathrm{HCV}$ infection may require up to 1 month or more for adequate antibody detection. Follow-up and/or confirmatory testing of HCV RNA for these patients may be warranted (Table 3). ${ }^{3,7}$ Retesting for both anti-HCV and HCV RNA in 4 to 6 months may help to resolve issues with false-positive and false-negative results. ${ }^{3,7}$

In June 2010, the FDA approved the first rapid blood test for antibodies to HCV (OraQuick®) HCV Rapid Antibody Test, OraSure Technologies). It is approved for use in patients' ages 15 years and older. The test is approved for screening in persons who are considered at risk for 
HCV infection and works from a sample of venous blood with readable results in about 20 minutes. $^{12-13}$

ALT and AST tests may appear normal or elevated in chronic infection. Elevations in ALT are more frequently seen, usually less than 5 but as high as 20 times the upper limit of normal. ${ }^{3}$

Liver biopsy is not needed to diagnose HCV but is useful in determining the grade and stage of liver disease. The grade of disease is determined by evidence of necrosis and inflammation in liver tissue whereas the stage is determined by the extent and presence of fibrosis and cirrhosis. At this time, the decision to obtain a liver biopsy for prognostic purposes or to guide a decision for treatment should be individualized taking into consideration the probability of disease progression, patient willingness to undergo the procedure and genotype. ${ }^{3,7}$

Genetic Variations

Six different genotypes and more than 50 subtypes exist for HCV. Genotype denotes nucleotide variation and is typically represented geographically by location for HCV. Genotype 1 is the most common in the U.S. followed by genotypes 2 and 3. Genotype 4 is most represented in the Middle East, including, Egypt and Africa whereas genotype 5 is seen in South Africa, and genotype 6 in Southeast Asia. ${ }^{14-15}$ Genotypic variations aid in identifying patients likely to respond to treatment and guide the duration of therapy, so it is important to guide therapeutic decisions. $^{3,7}$

\section{Therapeutic Management}

The management of chronic HCV should be individualized. Methods to prevent transmission and the importance of adherence to treatment should be addressed. Treatment is strongly recommended and should be considered in patients with chronic HCV and detectable levels of HCV RNA, elevated aminotransferase levels and histologic evidence of progressive liver disease. $^{7,16}$

The primary goals of therapy are to prevent complications and death from HCV while reducing adverse events and maintaining quality of life. The difficulty in achieving these goals is complicated by the slow progression of chronic disease and treatment responses that are based on surrogate virological parameters versus long-term clinical outcomes. Normalization of serum aminotransferase levels, virologic response and histological improvement are several short-term outcomes commonly assessed. ${ }^{7}$

"Virologic cure" is established by a sustained virologic response (SVR), defined as the absence of serum HCV RNA by PCR assay 24 weeks following cessation of therapy. ${ }^{7}$ SVR offers the best prediction of long-term response. Lack of an early virologic response (EVR) can be used to predict non-responders and a lack of SVR. Evaluation of rapid virologic response (RVR) can be 
used to assess durations of treatment based on genotype. All possible virologic responses are defined in Table $4 .^{7}$

Alfa interferon or interferon alfa-2b (Intron A, Schering Corp., 1986) was the first therapy approved for the treatment of $\mathrm{HCV} .{ }^{17}$ The limitations with this standard, non-pegylated interferon included rapid absorption in subcutaneous tissue, a large volume of distribution, rapid renal elimination, a short half-life and variable peak-trough concentrations. ${ }^{16}$ These unfavorable characteristics necessitated dosing three times weekly. The later addition of a polyethylene glycol (pegylated) moiety resolved many of these issues. Ribavirin, an oral synthetic nucleoside analogue, acts synergistically with pegylated interferon is administered in divided doses. Ribavirin is not effective or indicated as monotherapy for treatment of HCV. ${ }^{18}$ The combination of pegylated interferon and ribavirin represent the current recommendations for the treatment of $\mathrm{HCV}$.

\section{Safety}

Treatment-limiting adverse effects are a common complication HCV treatment and are experienced by most patients. Adverse events may lead to dosage reductions or treatment discontinuation. The most common side effects (incidence varies, 20-40\%) include flu-like effects (fatigue, headache, fever), gastrointestinal effects (nausea, anorexia, diarrhea) and psychiatric effects (irritability, depression, insomnia). Psychiatric effects can be managed with frequent assessment and counseling. Selective serotonin reuptake inhibitors can be used to treat depression. Agent selection should address hepatic dysfunction and drug interactions. Laboratory abnormalities such as neutropenia (absolute neutrophil count [ANC] $<1500 \mathrm{~mm}^{3}$ ) and anemia also frequently lead to dosage reductions and/or treatment discontinuation. The use of granulocyte colony stimulating factors is usually not necessary except in cases of advanced cirrhosis. Likewise, growth factors such as erythropoietin and darbepoietin should be used cautiously in light of the potential for serious cardiac and thromboembolic events and increased costs. Their use has not been associated with better clinical outcomes in $\mathrm{HCV}$, including attainment of SVR. ${ }^{7,18-20}$

Significant safety concerns exist with all interferon products. A black box warning highlights the potential for causing or aggravating fatal or life-threatening neuropsychiatric, autoimmune, ischemic and infectious disorders. Patients require careful monitoring and observation while receiving these therapies. Therapy should be discontinued in patients with persistently severe or worsening signs or symptoms of any of the mentioned conditions. Contraindications to the use of interferon include hepatic decompensation as evidenced by a Child-Pugh score of $>6$ (Class B or $\mathrm{C}$ ) in cirrhotic patients before or during treatment. Routine monitoring of complete blood counts (CBC) and liver function tests (LFTs), including pre-treatment and routinely thereafter is necessary. Dosage reductions should be considered in patients with hematologic abnormalities, moderate depression, renal dysfunction or if transaminase levels flare. Severe depression 
warrants discontinuation of therapy. Individual prescribing information should be consulted for specific recommendations for dosage reductions associated with each alfa interferon product. ${ }^{19-20}$

Ribavirin carries a black box warning regarding its potential to cause birth defects and fetal death. It is rated as Pregnancy Category $\mathrm{X}$ and is contraindicated in pregnant women and men whose female partners are pregnant. Women of childbearing age and men must use 2 effective forms of contraception during the treatment period and for 6 months following treatment. Routine monthly monitoring of pregnancy tests is also required. A toll-free hotline to a Ribavirin Pregnancy Registry was established to monitor maternal and fetal outcomes of pregnant women exposed to ribavirin. ${ }^{19-20}$

Other serious effects with ribavirin highlighted in a black box warning include the risk of hemolytic anemia which may result in worsening cardiac disease. Because of the risk of hemolytic anemia, a CBC should be obtained pretreatment and at a minimum, weeks 2 and 4 of therapy. Patients with pre-existing cardiac disease need to have an echocardiogram before treatment and should be closely monitored. Dosage reductions are determined by laboratory values, specifically for anemia in the presence or absence of cardiac history. Ribavirin is also contraindicated in patients with a history of hypersensitivity to ribavirin or any component of the formulation and should not be used in patients with a creatinine clearance $(\mathrm{CrCl})<50 \mathrm{~mL} / \mathrm{min}^{18}$

Current Treatment Regimens

All patients with chronic $\mathrm{HCV}$ should be evaluated for treatment with peginterferon and ribavirin. Depending on HCV genotype, the duration of therapy will be determined. Patients with genotype 1 infection typically have an SVR rate varying around 40 to 55\%, whereas those with genotypes 2 or 3 have higher rates at 70 to $90 \% \cdot{ }^{21-22}$ Genotypes $1 \& 4$ require treatment for 48 weeks while those with genotype 2 or 3 can receive 24 weeks of therapy. ${ }^{7}$ Given the complexity and breadth of literature in patients receiving retreatment of $\mathrm{HCV}$ post liver transplantation, studies focused in that area of practice are not included in the scope of this review.

Recent clinical studies evaluating various treatment strategies are summarized in Tables 5 and $6{ }^{23-38}$ Most studies were conducted in treatment naïve patients with detectable HCV RNA, histologic findings consistent with chronic HCV and elevated ALT levels. Study analyses were conducted as intention-to-treat unless otherwise noted. All studies were approved by institutional review or in accordance with the Helsinki Declaration of 1975.

\section{Comparative Efficacy of Pegylated Interferons}

Currently, two pegylated interferons are FDA approved for treatment of HCV, peginterferon alfa-2a (Pegasys, Hoffman-La Roche, 2002) and peginterferon alfa-2b (Peg-Intron, Schering Corp., 2001) ${ }^{17}$ Though both agents are routinely prescribed for treatment, their dosing regimens and pharmacokinetics differ. Peginterferon alfa- $2 \mathrm{~b}$ is dosed according to body weight, whereas peginterferon alfa-2a is a fixed dose. Both regimens are dosed subcutaneously once weekly; 
however, their half-lives are different. Peginterferon alfa- $2 b$ has a 40 hour mean elimination halflife, and peginterferon alfa-2a has a plasma half-life ranging from 80 to 160 hours. ${ }^{19-20}$ These differences in half-lives have corresponded to reduced or absent plasma concentrations at 7 days and variable peak-trough ratios with peginterferon alfa- $2 b .{ }^{23}$ Until recent studies, it was uncertain whether these differences significantly impacted treatment outcomes. The efficacy and safety of both pegylated interferons have been studied in several recent prospective, randomized, clinical trials (Table 5). ${ }^{23-33}$ Standard dosing of peginterferon alfa- $2 \mathrm{a}$ at $180 \mu \mathrm{g}$ and peginterferon alfa-2b at $1.5 \mu \mathrm{g} / \mathrm{kg}$ subcutaneously once weekly were utilized in all studies unless otherwise noted.

Di Bisceglie et al. ${ }^{23}$ conducted a prospective, randomized open-label study to compare viral kinetics and HCV RNA response at 12 weeks between peginterferon alfa-2a and peginterferon alfa-2b in combination with ribavirin. Patients with genotype 1 and viral load $\geq 800000 \mathrm{IU} / \mathrm{mL}$ were evaluated. Weight-based dosing of ribavirin (1000 and $1200 \mathrm{mg}$ for weights $\leq 75 \mathrm{~kg}$ and $>75 \mathrm{~kg}$, respectively) was used. Standard dosing of peginterferon alfa-2a and peginterferon alfa$2 \mathrm{~b}$ was utilized. The primary endpoint, HCV RNA over time, was comparable between both groups at all time points. Similarly, the number of patients who achieved RVR was similar. More patients withdrew treatment in the peginterferon alfa-2b arm (5.7\% vs. $1 \%)$ for safety reasons such as rash, anemia, suicidal ideation, depression, influenza-like symptoms, among various others. However, no significant differences in overall safety outcomes were noted. The peginterferon alfa-2b group experienced more influenza-like illness, chills, fever, rash and vomiting, whereas the peginterferon alfa-2a group had more dyspnea reported. Neutropenia (Grade 3 or greater) occurred in $43.4 \%$ of patients in the peginterferon alfa-2a group vs. $34.8 \%$ in the peginterferon alfa-2b group.

Another study compared peginterferon alfa-2a and peginterferon alfa- $2 b$ for differences in SVR in treatment-naïve patients with chronic HCV. ${ }^{24}$ This was a prospective, randomized open-label study. Weight-based ribavirin was utilized (<65 kg: $800 \mathrm{mg} /$ day; $65-75 \mathrm{~kg}$ : $1000 \mathrm{mg} /$ day; >75 $\mathrm{kg}$ : $1200 \mathrm{mg} / \mathrm{day})$. The duration of treatment was 24 weeks for genotypes $2 / 3$ and 48 weeks for genotypes 1/4. Results showed that SVR rates were similar among groups, $65.9 \%$ in the peginterferon alfa- $2 \mathrm{a}$ arm and $62 \%$ with peginterferon alfa- $2 \mathrm{~b}(\mathrm{p}=0.64)$. Differences between genotypes according to treatment group were also not significant with more than $45 \%$ of genotype 1 achieving SVR and more than $80 \%$ of genotypes $2 / 3$ and 4 .

A third arm of the Individualized Dosing Efficacy vs. Flat Dosing to Assess Optimal Pegylated Interferon Therapy (IDEAL) study was undertaken to evaluate the safety and efficacy of standard peginterferon alfa- $2 a$, standard peginterferon alfa- $2 b$, and low-dose peginterferon alfa$2 \mathrm{~b}$ in 3070 treatment-naïve patients with genotype $1 \mathrm{HCV} \cdot{ }^{25}$ Low-dose peginterferon alfa- $2 \mathrm{~b}$ consisted of $1.0 \mu \mathrm{g} / \mathrm{kg}$ weekly. All regimens were in combination with weight-based ribavirin; however, the dose differed according to which interferon product was used. Ribavirin was dosed in the following manner for peginterferon alfa-2b: 40-65 kg: $800 \mathrm{mg} / \mathrm{day} ;>65-85 \mathrm{~kg}$ : 1000 mg/day; >85-105 kg: 1200 mg/day; >105-125 kg: 1400 mg/day. Peginterferon alfa-2a received ribavirin $1000 \mathrm{mg} /$ day for weight $<75 \mathrm{~kg}$ and $1200 \mathrm{mg} /$ day for weight $\geq 75 \mathrm{~kg}$. Different ribavirin 
regimens were utilized based on the current prescribing information at the time of the study. The treatment duration was 48 weeks. The primary endpoint was SVR and two superiority analyses were conducted comparing the two dosage regimens of peginterferon alfa- $2 \mathrm{~b}$ and standard peginterferon alfa-2b vs. peginterferon alfa-2a.

Rates of SVR were similar among all three groups [39.8\% for standard peginterferon alfa-2b; $38 \%$ for low-dose peginterferon alfa- $2 \mathrm{~b}(\mathrm{p}=0.20) ; 40.9 \%$ for peginterferon alfa- $2 \mathrm{a}(\mathrm{p}=0.57)]$. Adverse events were also similar in type and frequency between all groups. Two deaths were considered to be possibly related to treatment, one with standard peginterferon alfa- $2 \mathrm{~b}$ (suicide) and one with peginterferon alfa-2a (myocardial infarction). ${ }^{25}$

\section{Duration of Therapy According to Genotype}

Given that peginterferon and ribavirin represent the established treatment for chronic HCV, much of the current research focuses on duration of therapy. Genetic differences have been heavily studied in relation to $\mathrm{HCV}$. The standard of evidence-based care has been to treat $\mathrm{HCV}$ patients with genotype 1/4 for 48 weeks and genotypes $2 / 3$ for 24 weeks. More recently, studies have focused on individualizing the duration according to RVR or EVR. The following studies highlight some of these recent findings.

Analysis of common predictors of SVR response was conducted in several of these studies. Factors such as age $\leq 45$ years, genotype 2, baseline HCV RNA level $\leq 400000 \mathrm{IU} / \mathrm{mL}$, weight $\leq 80 \mathrm{~kg}$, ALT levels, and degree of fibrosis were all predictive of SVR. ${ }^{26,28-30,32}$

Factors to consider with many of these studies is that though overall SVR rates may not differ, relapse rates and rates of discontinuation may be balancing the results. This, in addition to differences in study design may be contributing to the lack of consistent results regarding the optimal durations of treatment according to genotype.

\section{Genotype 1}

A prospective, open-label German study of genotype 1 patients randomized to standard peginterferon alfa-2a in addition to ribavirin ( $800 \mathrm{mg}$ /day) for either 48 (Group A) or 72 weeks (Group B) aimed to evaluate differences in SVR and relapse rates. ${ }^{26}$ The study utilized fixeddose ribavirin. The primary efficacy measure, SVR, was similar in both groups (53\% for 48 weeks, $54 \%$ for 72 weeks, $\mathrm{p}=0.8$ ), highlighting that duration of therapy did not translate into higher SVR rates. In addition, significantly more patients in Group B prematurely discontinued therapy $(\mathrm{p}<0.001)$.

Patients who had detectable HCV RNA levels at week 12 achieved significantly higher SVR rates with 72 weeks of treatment vs. 48 (29\% and $17 \%$, respectively, $\mathrm{p}=0.04)$ whereas those who had undetectable levels at weeks 4 or 12 reached SVR rates as high as $84 \%$, independent of treatment duration. This demonstrated that patients considered "slow responders" to therapy, 
may benefit from extended treatment. Benefits of extended treatment on relapse rates were also noted in other patients who were considered slow responders (HCV-RNA detectable at weeks 4 or 12) but HCV-RNA undetectable at week 12 (37\% vs. 23\%, Groups A and B, respectively, $\mathrm{p}=0.016)$ and week 24 (64\% vs. 40\%, Groups A and B, respectively, $\mathrm{p}=0.021)$. Rates of relapse were similar between groups (Group A, 29\% and Group B, 21\%, p=0.13). Adverse events did not differ between both treatment groups; however, more patients treated for 72 weeks discontinued therapy as compared to 48 weeks. ${ }^{26}$

A similar study was conducted in the U.S. to evaluate extended treatment (48 vs. 72 weeks) in treatment naïve, genotype 1 patients treated with peginterferon alfa- $2 \mathrm{~b}$ in combination with weight-based ribavirin ( $\leq 64 \mathrm{~kg}$ : $800 \mathrm{mg}$; 64-84 kg: $1000 \mathrm{mg} ; 85-104 \mathrm{~kg}: 1200 \mathrm{mg}$; $\geq 105 \mathrm{~kg}$ : $1400 \mathrm{mg}$ ). ${ }^{27}$ Before randomization, patients were determined to be slow responders, defined as at least a 2-log reduction in HCV RNA and undetectable levels at week 24. The primary endpoint, SVR, was statistically higher in the extended treatment arm receiving 48 weeks of additional treatment $(38 \%)$ versus those treated for an additional 24 weeks $(18 \%, \mathrm{p}=0.03)$. A lower relapse rate was also found with the extended duration $(20 \%$ vs. $59 \%, \mathrm{p}=0.004)$. Adverse effects or rates of discontinuation did not differ significantly among groups.

A noninferiority study conducted in Italy evaluated the efficacy of peginterferon alfa- $2 \mathrm{a}$ or peginterferon alfa- $2 b$ combined with ribavirin in standard vs. extended treatment in patients with genotype $1 .{ }^{28}$ Weight-based ribavirin was dosed at $1000 \mathrm{mg} /$ day for patients weighing $\leq 75 \mathrm{~kg}$ and $1200 \mathrm{mg}$ if weight was $>75 \mathrm{~kg}$. Patients were randomized to 48 weeks of therapy or to an individualized duration based on virologic response during the initial 12 weeks of therapy. Patients in the individualized group who achieved RVR were treated for 24 weeks, and those achieving undetectable HCV RNA levels at 8 and 12 weeks were treated for 48 and 72 weeks, respectively.

Sustained virologic response rates occurred in $45.1 \%$ of patients in the standard group and $48.8 \%$ in the individualized group ( $\mathrm{p}=0.37$ ). This met the criteria for establishing noninferiority. Patients who achieved RVR had SVR rates of $87 \%$ after 48 weeks of treatment and $77.2 \%$ after 24 weeks of treatment in the individualized group $(\mathrm{p}=0.12)$. Patients achieving undetectable HCV RNA levels at week 12 showed a greater overall SVR response when randomized to the 72 week duration rather than 48 weeks (63.4\% vs. 38.1\%, respectively). Relapse rates, adverse events, and virologic responses according to duration and peginterferon were also similar. More patients in the individualized group discontinued therapy. The authors concluded that these findings warrant larger studies to determine the benefit of individualized therapy based on 12 week response. ${ }^{28}$

Lastly, a study in patients with genotype 1 or 4 to evaluate a 24 week regimen after achieving RVR was conducted in Austria and utilized peginterferon alfa-2a in combination with ribavirin (1000-1200 mg/day). ${ }^{29}$ Patients who achieved RVR were assigned to 24 weeks of therapy. Results showed overall SVR rates of $76.7 \%$. These results were the first reported of a larger 
study involving 516 patients that will also evaluate treatment durations of 24,48 and 72 weeks dependent upon virologic response.

Cumulatively, the results of these recent studies recognize possible alternative durations of therapy in HCV genotype 1 patients, dependent upon virologic response, both RVR and EVR. For slow responding patients, commonly determined by week 12 and 24, a longer duration of treatment, up to 72 weeks, may be beneficial. Those patients with genotype 1 who achieve RVR may be candidates for 24 weeks of treatment. However, more conclusive evidence and larger studies need to be conducted to confirm these findings.

\section{Genotype 2/3}

Several small studies have found SVR rates of $80 \%$ or higher in patients with genotype 2/3 HCV after achieving RVR at 4 weeks and being treated with 12 to 16 weeks of therapy. ${ }^{39-42}$ Differences in these studies, including treatment duration, ribavirin dosing, population characteristics and study design have made it difficult to use these findings as evidence to support a shortened duration of therapy for these patients. Though the concept of a shortened duration based on genotype and virologic response aims at reducing unnecessary treatment and adverse effects, some recent studies have shown attenuated efficacy when compared to the standard 24 weeks of therapy.

A 2008 study sought to compare the efficacy of 12 or 24 weeks of therapy in patients with genotype 2/3. ${ }^{31}$ This was a randomized, open-label, phase III, multicenter study. Peginterferon alfa-2a and ribavirin $800 \mathrm{mg}$ daily were administered. Results showed that 12 weeks of therapy was inferior to 24 weeks in relation to SVR rates (59\% vs. 78\%, respectively, p<0.0001). Also, a higher relapse rate was noted with 12 weeks (33\% vs. 12\%, p<0.0001). Adverse events leading to discontinuation of therapy occurred more frequently in the 24 week arm $(\mathrm{p}<0.0001)$.

Another study randomized patients with genotype $2 / 3$ to receive peginterferon alfa- $2 \mathrm{~b}$ in combination with weight-based ribavirin (<65 kg: 800 mg/day; 65-85 kg: $1000 \mathrm{mg} /$ day; 86-105 $\mathrm{kg}$ : $1200 \mathrm{mg} /$ day; >105 kg: $1400 \mathrm{mg} /$ day) for a treatment duration of 14 or 24 weeks dependent upon virologic response. ${ }^{32}$ Patients who achieved RVR were randomized to either 14 (Group A) or 24 weeks (Group B) of treatment, and patients not achieving RVR received 24 weeks (Group C) of therapy. This was an open-label, noninferiority study to evaluate SVR. Noninferiority could be established if the upper limit of the $95 \%$ CI was below the margin of $10 \%$. The majority $(80 \%)$ of patients were infected with genotype 3. Results showed that Group A had an SVR rate of $81.1 \%$ and Group B achieved SVR in $90.7 \%$ (95\% CI, 1.7-17.7), not establishing noninferiority. When adjusted to include only patients with HCV RNA determination 24 weeks after the end of treatment SVR rates were similar (86.3\% in Group A and 93.2\% in Group B). Patients in Group A experienced higher relapse rates over Group B (10.8\% vs. 5.3\%), but Group $\mathrm{B}$ had higher rates of discontinuation. The incidence of adverse effects did not differ significantly between groups. 
The Accelerate Trial is the largest study to date regarding shortened duration in genotypes 2 or 3 . Efficacy was assessed in this large, international study conducted in 1469 patients. ${ }^{30}$ Patients were randomized to receive 16 or 24 weeks of therapy with peginterferon alfa-2a and ribavirin (400 mg twice daily). The study was designed as a per-protocol, noninferiority analysis with a margin for noninferiority set at $6 \%$. Overall results failed to demonstrate noninferiority.

Sustained virologic response rates were $65 \%$ in the 16 week group as compared to $76 \%$ in the 24 week group $(\mathrm{p}<0.001)$. A significantly higher relapse rate occurred in the 16 week group as well ( $31 \%$ vs. $18 \%$ ), p<0.001). Anemia and neutropenia were the most common cause of dose reductions. More patients in the 24 week group required dose reductions in ribavirin (23\% vs. $17 \%, \mathrm{p}=0.01)$.

\section{Genotypes 4/5}

Few robust studies solely conducted in patients with genotype 4 and 5 exist. Though genotypes 1 and 4 are thought to be similar, a recent prospective, uncontrolled study in 30 patients from the Middle East with genotype 4 demonstrated that treatment with peginterferon alfa- $2 \mathrm{a}$ in combination with weight-based ribavirin (1000 mg/day for patients weighing $<75 \mathrm{~kg}$ and 1200 mg if weight was $>75 \mathrm{~kg}$ ) for 48 weeks resulted in a SVR in $63.6 \%$ of patients which was slightly higher than normally observed SVR rates for genotype $1 .{ }^{15}$

A 2008 study conducted in Syrian patients with genotype 5 retrospectively evaluated 26 patients who received ribavirin (1000 to $1200 \mathrm{mg}$ /day) in combination with interferon alfa-2a (3 million units three times weekly) or peginterferon alfa-2a at standard dosages. Patients were treated for 24 or 48 weeks. More patients received standard interferon (65\%) vs. pegylated interferon (35\%). Results showed SVR was attained in $47 \%$ of patients with interferon vs. $67 \%$ with pegylated interferon $(p=0.43)$. Higher rates were also achieved with 48 weeks of treatment. ${ }^{43}$

\section{Genotype 6}

Limited evidence exists regarding the appropriate duration of therapy for patients with genotype 6. One small, retrospective cohort study was conducted to evaluate peginterferon in addition to ribavirin for 24 or 48 weeks in this population. ${ }^{33}$ The dosing schema was a) interferon alfa-2b ( 3 million units three times weekly) in combination with ribavirin (1000 mg/day) b) weight-based peginterferon alfa- $2 \mathrm{~b}(80-150 \mu \mathrm{g})$ with weight-based ribavirin $(800-1200 \mathrm{mg} /$ day $)$ or c) peginterferon alfa-2a (180 $\mu$ g weekly) with ribavirin (1000-1200 mg/day) . In total, 23 patients were treated for 24 weeks and 12 patients completed 48 weeks. The majority of patients were Asian-American. Results showed SVR rates of $39 \%$ vs. $75 \%$ for those treated for 24 and 48 weeks, respectively $(\mathrm{p}=0.044)$. The results of this study need to be confirmed with larger, prospective studies in this population.

Overall the results of studies in patients with HCV genotype 2, 3 or 6 indicate that treatment duration of 24 weeks remains the most appropriate. Shorter durations are associated with relapse and lower SVR rates. 


\section{Relapsers and Non-Responders}

Patients who do not respond to the current standard of therapy have been less studied. Early studies evaluated clinical response to peginterferon in addition to ribavirin after failing treatment with interferon, and more recent studies aim to evaluate retreatment following treatment failure with pegylated interferon. ${ }^{44}$ Current U.S. guidelines do not strongly advocate retreatment of patients who previously fail to respond to initial therapy. ${ }^{7}$ Though consistent results are lacking and need to be confirmed with larger studies, potential situations for retreatment exist, including in those patients who previously failed therapy with non-pegylated interferon.

The EPIC Study (Evaluation of PegIntron in Control of Hepatitis C) was a large, international, multicenter, open-label study conducted to evaluate the retreatment of patients with chronic $\mathrm{HCV}$ who previously failed therapy with peginterferon or non-pegylated interferon therapy in combination with ribavirin. ${ }^{45}$ Patients qualified for retreatment if they presented with significant hepatic fibrosis or cirrhosis and needed to receive at least 12 weeks of combination therapy without achieving SVR. Patients received standard peginterferon alfa- $2 \mathrm{~b}$ in combination with weight-based ribavirin for 48 weeks. The majority of patients were Caucasian males with genotype $1 \mathrm{HCV}$, viral loads $>600000 \mathrm{IU} / \mathrm{mL}$, and were nonresponders to previous treatment with interferon therapy in combination with ribavirin. Overall, $22 \%$ of patients achieved SVR with a greater response observed in relapsers vs. non-responders (38\% vs. 14\%, respectively) regardless of previous treatment. Furthermore, patients who previously received interferon therapy responded better than those who received pegylated interferon $(25 \%$ vs. $17 \%$, respectively). Genotype, viral load at baseline, stage of fibrosis, previous treatment regimen and previous response were found to be significant predictors of response.

Extending the treatment duration of therapy may be a viable option in HCV non-responders following treatment with peginterferon and ribavirin. One study was conducted to investigate the use of peginterferon alfa-2a with ribavirin to retreat non-responders to peginterferon alfa- $2 b$ in combination with ribavirin. ${ }^{46}$ This parallel-group, international study randomly assigned patients to 1 of 4 possible open-label treatment groups. Group A received peginterferon alfa-2a, 360 $\mu \mathrm{g} /$ week for 12 weeks followed by $180 \mu \mathrm{g} /$ week to complete 72 weeks of treatment or 48 weeks of treatment (Group B). Group C received peginterferon alfa-2a, $180 \mu \mathrm{g} /$ week for 72 weeks or 48 weeks (Group D). All patients received ribavirin (1000 or $1200 \mathrm{mg}$ daily). The majority of patients had genotype 1. The rate of SVR in Group A was 16\% vs. $9 \%$ in Group D ( $\mathrm{p}=0.006$ ). SVR rates were $7 \%$ in Group B and $16 \%$ in Group C. More patients in treatment Group A and C benefited from extended durations but withdrew treatment early. Additionally, the overall rate of serious adverse events was higher in patients assigned to 72 weeks of therapy. The results of this study demonstrated the possibility of extended treatment in non-responders to peginterferon therapy; however, the withdrawal rate and risk of adverse events needs to be considered.

Patients who relapse or those who do not respond to initial peginterferon and ribavirin therapy need to be adequately assessed prior to initiating retreatment. Previous response (non-response, 
relapse, and breakthrough) needs to be assessed. Also, modifiable risk factors affecting treatment should be identified, including adherence to treatment, body weight and alcohol abuse. ${ }^{44}$

Alternative and Investigational Therapies

Several new therapies are in development for the treatment of HCV (Table 6). ${ }^{34-38}$ Additionally, targeted HCV inhibitors are promising agents for future treatment. ${ }^{47}$

\section{Albinterferon}

A new interferon product, albinterferon, consists of interferon alfa-2b genetically fused to recombinant human albumin, allowing for a more convenient dosing schedule (once or twice monthly). ${ }^{34,47}$ Albinterferon alfa-2b is an 85.7 kilodalton $(\mathrm{kDa})$ protein with an estimated halflife of 150 hours. ${ }^{34-35}$ Albinterferon is currently in phase I studies in the U.S. for the treatment of $\mathrm{HCV}$ in patients with HIV co-infection. No studies have evaluated use of albinterferon in patients with renal dysfunction. Several other countries are in phase III of development for the use of albinterferon as combination therapy in treatment naïve patients with $\mathrm{HCV}^{48}$

An open-label, phase III, multicenter trial investigated dosing strategies, efficacy, safety and patient reported health-related quality of life (HRQOL) of albinterferon alfa-2b compared to peginterferon alfa- $2 \mathrm{a}$ in previously untreated patients with genotype $1 .{ }^{34}$ Patients were randomized to 1 of 4 treatment groups, including albinterferon $900 \mu \mathrm{g}$ subcutaneously once every 2 weeks, albinterferon $1200 \mu \mathrm{g}$ once every 2 weeks, albinterferon $1200 \mu \mathrm{g}$ once every 4 weeks or active control, or peginterferon alfa-2a $180 \mu \mathrm{g}$ subcutaneously once weekly. In addition, all patients received weight-based ribavirin ( $1000 \mathrm{mg} /$ day if $<75 \mathrm{~kg}$ or $1200 \mathrm{mg} /$ day if $\geq 75 \mathrm{~kg}$ ). The duration of treatment was 48 weeks.

Results of the primary and secondary efficacy endpoints, including SVR, relapse rate, and breakthrough rate demonstrated no significant difference between the albinterferon groups and peginterferon alfa-2a. SVR ranged from 55 to $58 \%$ in the intention-to-treat analysis of all groups $(\mathrm{p}=0.64)$ Rates of adverse events were similar among all groups with the exception of the albinterferon $1200 \mu \mathrm{g}$ every 2 week group, which experienced a higher rate and more severe adverse effects. Rates of discontinuation were also higher in this group $(\mathrm{p}=0.04)$. Hematologic abnormalities were comparable across groups except for the albinterferon $1200 \mu \mathrm{g}$ every 4 week group, which had significantly lower rates of events $(\mathrm{p}<0.05)$. Health-related quality of life was significantly favorable in the albinterferon $900 \mu \mathrm{g}$ every 2 week treatment group as compared to peginterferon alfa-2a in terms of scores and missed workdays $(\mathrm{p}<0.05){ }^{34}$

Another phase II, open-label, multicenter trial conducted in 43 treatment naïve patients with genotypes $2 / 3$ was aimed at evaluating the safety of different dosages of albinterferon alfa- $2 b$ in combination with ribavirin. ${ }^{35}$ In contrast to the previous study, a higher dosage of albinterferon was utilized $(1500 \mu \mathrm{g})$ every 2 or 4 weeks. In addition to assessing efficacy and safety, this study 
sought to determine if an association exists between insulin resistance and antiviral response in patients with genotype $2 / 3$. The treatment duration was 24 weeks.

Rates of SVR were $77.3 \%$ for the every 4 week treatment arm versus $61.9 \%$ for the every 2 week $\operatorname{arm}(\mathrm{p}=0.27)$. The lower response in the every 2 week arm was attributed to a higher discontinuation rate unrelated to treatment. Insulin resistance, estimated by homeostasis model assessment of insulin resistance (HOMA-IR), was determined if the HOMA-IR score was $>2$. Patients who demonstrated insulin resistance according to these methods exhibited a lower SVR as compared to those patients without insulin resistance $(42.9 \%$ and $88.2 \%$, respectively, $\mathrm{p}=0.02){ }^{35}$

No significant differences were found between both dosage regimens in terms of safety and tolerability. Some of the most frequently reported moderate-severe adverse events included headache, fatigue, chills, myalgia, nausea, pyrexia, decreased weight, back pain, altered mood and arthralgia which did not different significantly between groups. Hematologic abnormalities did not differ; however, a greater incidence of lower ANC was found in the $1500 \mu \mathrm{g}$ every 2 week treatment group as compared to the every 4 week group $(23.8 \%$ versus $9.1 \%$, respectively, $\mathrm{p}=0.24)$. No reductions in hemoglobin $<10 \mathrm{~g} / \mathrm{dL}$ or platelet counts $<50000 / \mathrm{mm}^{3}$ occurred. Additionally, no patients in the every 4 week treatment arm required dosage reductions due to hematologic effects. ${ }^{35}$

\section{Taribavirin}

Taribavirin, a prodrug of ribavirin, is also being studied for the treatment of chronic HCV with the benefit of a lower incidence of anemia. ${ }^{47,49}$ The major conversion site of taribavirin is in the liver, enabling this drug to concentrate in this location. Taribavirin contains a positively charged 3-carboxymide group, which prohibits its uptake in red blood cells and is thus associated with less hemolytic anemia. ${ }^{36,49-50}$ Taribavirin is currently in phase II testing in the U.S. for treatment of chronic $\mathrm{HCV}$ in combination with peginterferon. ${ }^{48,50}$

A phase II noninferiority study evaluating the use of taribavirin (800 to $1600 \mathrm{mg}$ daily) versus ribavirin (1000 to $1200 \mathrm{mg}$ daily) in combination with peginterferon yielded results of lower SVR rates with taribavirin; however, it did prove to be noninferior to ribavirin (23 to $37 \%$, respectively versus $44 \%$ with ribavirin, $\mathrm{p}=0.155) .{ }^{36,49}$ Lower rates of severe anemia were noted with taribavirin vs. ribavirin ( $4 \%$ vs. $27 \%)$.

Subsequent phase III studies (VISER 1 and VISER 2) evaluated taribavirin (600 mg twice daily) compared with ribavirin (1000 to $1200 \mathrm{mg}$ /day based on weight) in treatment naïve patients with all genotypes in combination with peginterferon alfa-2a. Results of these studies failed to demonstrate noninferiority of taribavirin to ribavirin in the intention-to-treat analysis. SVR rates were $38 \%$ with taribavirin and 52\% with ribavirin in VISER 1 and $40 \%$ versus $55 \%$ in VISER 2, respectively. In both studies, taribavirin did have lower rates of anemia (5\% vs. $24 \%$ and $6 \%$ vs. $22 \%$ ); however, in VISER 2, more patients receiving taribavirin experienced moderate to severe 
diarrhea (29.5\% vs. $15.7 \%, \mathrm{p}<0.0001)$. Though these studies were powered based on phase II SVR rates, the authors concluded that noninferiority may not have been established due to suboptimal dosing of taribavirin. Because ribavirin is most appropriately dosed based on weight, the theory that taribavirin may prove more effective with weight-based dosing has yet to be proven. $^{37,49}$

An unpublished phase IIb study was initiated based on post-hoc findings that weight-based taribavirin may prove more effective than standard dosing. This study evaluated 275 treatment naïve patients with genotype $1 \mathrm{HCV}$. Taribavirin at dosages of 20,25 , or $30 \mathrm{mg} / \mathrm{kg} / \mathrm{day}$ were compared with ribavirin in addition to peginterferon. End of treatment response rates after 48 weeks of treatment were reported as $43.4 \%, 32.9 \%, 29.4 \%$ for taribavirin, respectively, and $32.9 \%$ for ribavirin. Rates of anemia were also lower in the taribavirin group $(13.4 \%, 15.7 \%$, $27.9 \%$ for taribavirin and $32.9 \%$ for ribavirin). ${ }^{49}$ The results of this study are promising and need to be confirmed in larger, well-designed studies.

\section{Protease Inhibitors}

Two protease inhibitors are in development targeted against chronic $\mathrm{HCV} .{ }^{47}$ Boceprevir (SCH 503034) and telaprevir (VX-950) are oral agents currently in phase III clinical trials in the U.S. Both antiviral therapies are reversible, selective NS3 protease inhibitors, which is an enzyme responsible for viral replication. ${ }^{51-53}$ Both agents have shown substantial reductions in viral load in phase I clinical studies. All studies thus far have been conducted in patients with genotype 1 (Table 6) ${ }^{34-38}$ More recent studies have evaluated the use of these agents as a retreatment option for patients previously unable to achieve or maintain SVR. ${ }^{38,54}$ Additive and synergistic effects in viral reduction and SVR have been noted with the combination of peginterferon, ribavirin and a protease inhibitor. Additionally, combination therapy has decreased the emergence of resistance with these agents. ${ }^{51,55-56}$ Adverse events noted to be more common with telaprevir include rash and pruritis. $51,53,55-56$

A phase I clinical study conducted in 26 patients with genotype 1, who were previous nonresponders to therapy, evaluated the safety and tolerability of boceprevir in combination with peginterferon alfa-2b. ${ }^{54}$ This randomized, open-label, crossover study evaluated 2 dosages of boceprevir over 3 dosing periods. One week of boceprevir monotherapy was followed by monotherapy with peginterferon alfa- $2 b$ for 2 weeks and then combination therapy of both agents for 2 weeks. A minimum 2 week washout period was incorporated between each dosing period. The two dosage regimens of boceprevir evaluated were $200 \mathrm{mg}$ three times daily and 400 $\mathrm{mg}$ three times daily. Peginterferon alfa- $2 \mathrm{~b}$ was administered at standard dosing of $1.5 \mu \mathrm{g} / \mathrm{kg}$ once weekly. Results of this study showed that boceprevir was well-tolerated. Combination therapy was associated with a higher incidence of headache, rigor and myalgia. Pharmacokinetic analyses showed only a slight increase in bioavailability for combination therapy as compared with low-dose boceprevir monotherapy, and no increase in area-under-the-curve (AUC) was noted during combination therapy with high-dose boceprevir as compared to monotherapy. 
A recently published international phase II study evaluated the use of telaprevir in genotype 1 patients previously not achieving or maintaining SVR with prior therapy. ${ }^{38}$ The study was a randomized, stratified study evaluating one of four possible treatment regimens on achievement of SVR. Telaprevir was administered as a single initial oral dose of $1125 \mathrm{mg}$ followed by $750 \mathrm{mg}$ every 8 hours, peginterferon alfa-2a was dosed at $180 \mu \mathrm{g}$ subcutaneously weekly, and ribavirin was dosed according to weight (1000 mg/day for weight $<75 \mathrm{~kg}$ and $1200 \mathrm{mg} /$ day if weight $\geq 75$ $\mathrm{kg}$ ). One group (T12PR24) received telaprevir in combination with peginterferon alfa- $2 \mathrm{a}$ and ribavirin for 12 weeks followed by placebo, peginterferon alfa-2a and ribavirin for an additional 12 weeks. Another group (T24PR48) received telaprevir in combination with peginterferon alfa$2 \mathrm{a}$ with ribavirin for 24 weeks followed by peginterferon alfa-2a and ribavirin for an additional 24 weeks. The T24P24 group received telaprevir and peginterferon alfa-2a for 24 weeks, and the PR48 (control) group received placebo plus peginterferon alfa- $2 \mathrm{a}$ in combination with ribavirin for 24 weeks, followed by peginterferon alfa-2a and ribavirin for an additional 24 weeks. The majority of patients were white males, average age 51 years, who had previously not responded to prior therapy.

Results showed SVR was statistically higher in each telaprevir group. Additionally, SVR rates were higher among patients who previously experienced relapse vs. nonresponders. Logistic regression analyses revealed SVR was associated with assignment to the shorter telaprevir courses combined with longer peginterferon/ribavirin, previously undetectable HCV RNA levels and low baseline viral load. Maculopapular rash and pruritis were more common in groups that received telaprevir. The median time to rash appearance was 7 to 28 days, and 18 patients (5\%) in the telaprevir group discontinued treatment due to rash. Additionally, patients in the telaprevir group were more likely to discontinue treatment due to adverse effects, with skin disorders the most common reason for discontinuation. A decrease in hemoglobin levels was observed more frequently in the telaprevir-based groups vs. controls. ${ }^{38}$

Overall, protease inhibitors hold promise in treating patients with chronic HCV. To date, all studies have focused on genotype 1, and more studies are beginning to evaluate the use of protease inhibitors as an option for retreatment vs. initial therapy. Broader patient populations and larger studies in the future will help to clarify the exact role of these agents in the treatment of $\mathrm{HCV}$.

\section{Special Considerations}

Human Immunodeficiency Virus

Patients co-infected with HIV and HCV represent a unique challenge to the treatment of HCV. A large number of patients infected with HIV are also infected or become infected with HCV, leading to increased susceptibility to adverse treatment and disease effects, resulting in higher morbidity and mortality. ${ }^{57}$ When patients with HIV are infected with $\mathrm{HCV}$, they are less likely to spontaneously clear the virus, and the rate of liver disease progression may be accelerated. ${ }^{57-60}$ 
Liver-related hospitalizations tripled for patients co-infected with HIV from 1994 to $2001{ }^{6}$ Clinical judgment needs to be utilized regarding which co-infected patients to treat. Risk of serious liver disease should be weighed against the risk of morbidity from adverse events and anticipated treatment response. ${ }^{7}$

Peginterferon alfa in combination with ribavirin at standard dosages for a duration of 48 weeks is the recommended treatment for HIV/HCV co-infected patients. ${ }^{7,57,59-60}$ Two meta-analyses of 6 to 7 randomized, controlled trials found that peginterferon in combination with ribavirin was shown to produce a higher probability of achieving SVR as compared to treatment with interferon or peginterferon monotherapy. ${ }^{57,60}$ Patients treated with peginterferon and ribavirin were less likely to withdraw from treatment and develop hepatic decompensation. ${ }^{57} \mathrm{SVR}$ rates for patients with HIV/HCV genotype $1 / 4$ were found to be $25 \%$ vs. $54 \%$ for genotypes $2 / 3 .^{60} \mathrm{~A}$ clinical outcome study of HIV/HCV co-infected patients in Spain showed that patients who achieved SVR had a lower rate of all-cause mortality, liver-related death and liver decompensation $(\mathrm{p}<0.05){ }^{59}$

Adverse effects and drug interactions with ribavirin are especially concerning in patients coinfected with HIV/HCV. Anemia and neutropenia are of particular concern and require careful monitoring, dosage adjustments, and supplemental therapy as appropriate. Drug interactions with antiretroviral therapy also require careful evaluation. Ribavirin can increase the activity and toxicity of didanosine and other nucleoside reverse transcriptase inhibitors (NRTIs), with the potential to cause mitochondrial toxicity and lactic acidosis. ${ }^{61}$ Other NRTIs that may interact via this mechanism include abacavir, lamivudine, stavudine, zalcitabine and zidovudine. For this reason, concomitant administration of didanosine and ribavirin is contraindicated and the other NRTIs should be used cautiously and only if the benefit of treatment outweighs the risk. Ribavirin can also reduce the effectiveness of stavudine and zidovudine. ${ }^{18}$ Additive pharmacodynamic drug interactions may also result in increased adverse effects, including the risk of anemia with coadministration of ribavirin and zidovudine, and the risk of hepatotoxicity with the administration of ribavirin and lamivudine or zidovudine. Reduced adherence due to drug interactions, adverse effects and poor tolerability should be assessed in every patient. Reducing and/or extending treatment durations and appropriate management of non-responders (treatment algorithms) in patients co-infected with HIV/HCV need to be more adequately studied before strong recommendations can be made in this population. ${ }^{62}$

\section{End Stage Renal Disease}

Infection with HCV is higher among patients with end-stage renal disease (ESRD). The approach to treatment in ESRD is different than in patients with normal renal function. Altered pharmacokinetics and drug-related toxicities are concerns. ${ }^{63}$ Both interferon and ribavirin are renally eliminated. Because ribavirin is not recommended for use in patients with moderate renal function impairment $(\mathrm{CrCl}<50 \mathrm{~mL} / \mathrm{min})$, most studies have evaluated the use of interferon monotherapy in patients with compromised renal function. ${ }^{18,64}$ Ribavirin is not removed by 
hemodialysis. In renal dysfunction, the half-life of interferon and peginterferon is increased by as much as $40 \%$ and the AUC is also increased by as much as $90 \%$ when compared to patients with normal renal function. For this reason, dosage reductions in patients with moderate to severe renal impairment are necessary. Important considerations for therapy in patients with ESRD include tolerance to adverse effects and the potential for increased toxicity, reduced adherence and treatment response. ${ }^{63}$

AASLD guidelines do recommend as class IIa recommendations careful monitoring and treatment at reduced dosages of peginterferon (2a: $135 \mu \mathrm{g} / \mathrm{week} ; 2 \mathrm{~b}: 1 \mu \mathrm{g} / \mathrm{kg} /$ week) and ribavirin (200-800 mg/day) in patients with severe kidney disease, and a IIb recommendation that dialysis patients be considered for treatment with standard interferon or reduced dose peginterferon. Ribavirin can be added at a markedly reduced dosage with careful monitoring for adverse effects, but it is a class IIb recommendation. The limited number of studies cited in support of using low-dose ribavirin in any setting of renal dysfunction $(\mathrm{CrCl}<50 \mathrm{~mL} / \mathrm{min})$ was associated with significant adverse effects, including hemolytic anemia and often involved the use of growth factors. ${ }^{7}$

Few prospective clinical studies exist evaluating the treatment of chronic HCV in patients with ESRD. Studies of treatment with conventional interferon monotherapy often included a very small number of patients and poor study design (observational studies). SVR rates were found to be lower in treatment-naïve patients with normal renal function (13 to 19\%) as compared to patients with renal impairment (33 to 37\%), which indicate interferon monotherapy may be more effective in patients with ESRD. ${ }^{63}$ Studies of peginterferon monotherapy in patients with ESRD have resulted in reduced tolerability and SVR rates ranging from 12 to $75 \%$. Comparative studies are needed to determine which therapy is associated with better treatment response and better tolerability. ${ }^{63-64} \mathrm{~A}$ meta-analysis of 20 prospective studies of interferon-based (non-pegylated) treatment in patients with ESRD and HCV revealed several characteristics associated with a higher likelihood of achieving SVR, including patients receiving a larger dose of interferon, a longer duration of treatment, full completion of treatment, female gender, lower HCV RNA and virologic response. ${ }^{65}$ More recent studies have begun focusing on the use of low-dose ribavirin in patients with ESRD often based on serum ribavirin concentrations; however, once again stronger evidence is needed prior to implementing this therapeutic strategy into routine practice. ${ }^{63-64,66}$

\section{Injection Drug Abuse}

Special considerations are necessary before initiating treatment for chronic HCV in patients with a history of injection drug abuse. These include evaluating the benefits of treatment, the risk of reinfection, comorbid psychiatric illness and adherence to therapy and monitoring, among others. ${ }^{7,67}$ Although some data indicates a lower rate of SVR is achieved in patients with IDU, the data is conflicting. ${ }^{67-68}$ A recent retrospective study showed no significant differences in efficacy in adherent patients with active IDU. ${ }^{68}$ The pharmacokinetics of methadone are not significantly altered by peginterferon. ${ }^{69}$ A study conducted in treatment of acute HCV in IDU 
has shown promising results on SVR and greater compliance with a short treatment regimen. This was a prospective, open-label non-randomized study in 23 patients with IDU and acute HCV who received peginterferon alfa- $2 b$ for 12 weeks. Results showed an overall SVR in 17 patients $(74 \%) .^{70}$

Pregnancy

Routine screening of all pregnant women for HCV infection is not recommended by AASLD or the American College of Obstetricians and Gynecologists. ${ }^{7,71}$ No evidence suggests that HCV infection will adversely affect pregnancy outcomes in terms of fetal or obstetric complications. ${ }^{72}$ Additionally, no specific agencies have guidelines for treatment or monitoring of HCV in pregnancy. Given that ribavirin is absolutely contraindicated in pregnant women and strict precautions must be undertaken to prevent pregnancy in women of child-bearing age, treatment must occur well before conception or after delivery. Because ribavirin has a multiple dose half life of 12 days, it can persist for up to 6 months in nonplasma compartments. For this reason, pregnancy must be avoided both during treatment with ribavirin and for 6 months following treatment in female patients and female partners of male patients. ${ }^{18}$

From 2003 to 2009, 351 pregnancies have been tracked in the Ribavirin Pregnancy Registry, 6 of which described birth outcomes with defects. Three of these exposures were direct exposure and 3 were as a result of indirect ribavirin exposure. Specific defects included 1 cardiac defect, 2 cases of torticollis, 1 case of glucose-6-phosphate dehydrogenase deficiency, 1 case of hypospadias and a case of polydactyly. A larger sample of patients from the registry is planned to assess the relative risk of birth defects associated with ribavirin. ${ }^{73}$ Interferon monotherapy has not been well-studied in pregnancy, and interferons are classified as Pregnancy Category C. Peginterferon alfa-2a contains benzyl alcohol. Interferons should be considered to have abortifacient potential. $^{19-20}$

Pediatrics

The emphasis on children with HCV is focused on promoting awareness, diagnosis and initiating early treatment. Since the implementation of routine blood screening, vertical transmission has replaced transfusion-associated $\mathrm{HCV}$ as the most common mode of $\mathrm{HCV}$ transmission in pediatrics the U.S. ${ }^{7}$ Maternal viral load is the most important factor associated with vertical transmission. ${ }^{74}$ Most children with HCV are asymptomatic, as in adults, and the standard therapy is peginterferon in combination with ribavirin. Peginterferon alfa-2b is FDA approved for patients' ages 3 years and older and is dosed at $60 \mu \mathrm{g} / \mathrm{m}^{2}$ subcutaneously weekly in combination with ribavirin $15 \mathrm{mg} / \mathrm{kg}$ daily. A treatment duration of 48 weeks is recommended as a class I recommendation by AASLD regardless of genotype. ${ }^{7}$ Treatment should be considered in the same manner as in adults, with additional consideration given to patient age, level in school and stress. 
Most children who undergo treatment tolerate therapy well, but adverse effects are commonly reported such as flu-like symptoms, pyrexia, headache, vomiting, fatigue and neutropenia. ${ }^{18,75-77}$ Studies have shown that pediatric patients, especially adolescents, who received ribavirin experienced suicidal ideation or attempted suicide more frequently than in adults ( $2.4 \%$ vs. $1 \%)$. This occurred both during treatment and follow-up. Additionally, weight loss (mean percentile decrease of 13\%) and decreased linear growth (mean percentile decrease of 9\%) occurred in pediatric patients treated for 48 weeks, which was mostly reversible during the 6 months after treatment. $^{18}$

An open label, noncontrolled study conducted by Wirth et al. was one of the earliest studies on the use of peginterferon alfa in the treatment of $\mathrm{HCV}$ in children ${ }^{76}$ In this study, 62 children, ages 2 to 17 years, were administered peginterferon alfa- $2 \mathrm{~b}, 1.5 \mu \mathrm{g} / \mathrm{kg}$ subcutaneously weekly in combination with ribavirin $15 \mathrm{mg} / \mathrm{kg}$ daily in two divided doses for 48 weeks. The majority of patients $(75.8 \%$ ) had genotype 1 . Overall rates of SVR were $59 \%$, including $47.8 \%$ of patients with genotype $1 \mathrm{HCV}$ and $100 \%$ of genotypes $2 / 3(\mathrm{p}=0.0003)$. Adverse events frequently reported included leucopenia (75.4\%), neutropenia (55.7\%), flu-like symptoms (82\%), and fever (51\%). Other events included weight loss (19.7\%), and temporary mood swings (14.8\%).

A more recent open-label study was conducted in 30 children, ages 3 to 16 years, to evaluate peginterferon alfa- $2 \mathrm{~b}, 1 \mu \mathrm{g} / \mathrm{kg}$ subcutaneously weekly in combination with ribavirin $15 \mathrm{mg} / \mathrm{kg}$ daily. ${ }^{77}$ In this study, children with genotype 1 were treated for 48 weeks and those with genotypes $2 / 3$ were treated for 24 weeks. Most patients had genotype 1 , were treatment naïve and acquired $\mathrm{HCV}$ via vertical transmission. Overall, SVR was attained in $50 \%$ of patients. Adverse effects included flu-like symptoms, fever, fatigue, headache, decreased appetite and weight loss. Body weight decreased in $20 \%$ of children (>5\% weight loss occurred in $7 \%$ ) but returned to baseline by week 48 . Growth was reduced by $1.6 \mathrm{~cm}$ in 22 of 26 children compared with the growth velocity $50^{\text {th }}$ percentile for age and sex but was entirely normal in the 6 months following treatment. Neutropenia (neutrophils $<1000 \times 10^{9}$ cells/L) occurred in 9 patients necessitating reductions in dosing. Further studies in children are needed to clarify treatment duration in genotypes $2 / 3$ and long-term clinical outcomes.

\section{Conclusion}

Treatment of patients with chronic HCV should be individualized with consideration given to prevention of transmission, risk factor modification as appropriate, adverse events and tolerability, adherence, and avoidance of complications. Current practice guidelines published by the AASLD represent the evidence-based standard for management of HCV. Currently, peginterferon and ribavirin represent the standard of care for treatment of chronic $\mathrm{HCV}$. A surrogate marker for clinical outcomes in $\mathrm{HCV}$ is sustained virologic response. Of the two currently available pegylated interferons, both are equally efficacious in attaining SVR. Duration of therapy is guided by HCV genotype and virologic response. Because of the high rate of RVR and SVR, genotypes 2 and 3 can be treated for 24 weeks. Genotypes 1 and 4 require 48 weeks 
duration of treatment. In all patients undergoing treatment, appropriate monitoring for serious treatment-related adverse effects must be conducted. Hematologic abnormalities, including anemia and neutropenia may require a reduction in dosage or withdrawal from treatment. New therapies in development for treatment of HCV have the potential to reduce adverse effects and improve outcomes. Special populations, including patients co-infected with HIV, patients with severe chronic kidney disease, injection drug users, pregnancy and pediatric patients should be closely monitored to prevent HCV related morbidity and mortality. 
Chronic Hepatitis $C \&$ Current Therapies 24

\section{ACKNOWLEDGMENTS}

None. 


\section{REFERENCES}

1. Centers for Disease Control and Prevention. Surveillance for acute viral hepatitis - United States, 2007. Surveillance Summaries, May 2009. MMWR 2009;58:SS-3.

2. Rodis J. Chronic hepatitis $\mathrm{C}$ virus infection: a review for pharmacists. J Am Pharm Assoc 2007;47(4):508-517.

3. National Institutes of Health. Chronic hepatitis C: current disease management. November 2006. Available from http://digestive.niddk.nih.gov/ddiseases/pubs/chronichepc/index.htm Accessed January 8, 2010.

4. Armstrong GL, Wasley A, Simard EP, McQuillan GM, Kuhnert WL, Alter MJ. The prevalence of hepatitis C virus infection in the United States, 1999 through 2002. Ann Intern Med 2006;144(10):705-14.

5. Centers for Disease Control and Prevention. Disease burden from viral hepatitis A, B, and C in the United States. Available from http://www.cdc.gov/hepatitis/statistics.htm Accessed January 1, 2010.

6. Grant WC, Jhaveri RR, McHutchison JG, Schulman KA, Kauf TL. Trends in healthcare resource use for hepatitis $\mathrm{C}$ virus infection in the United States. Hepatology 2005;42(6):1406-13.

7. Ghany MG, Strader DB, Thomas DL, Seeff LB. Diagnosis, management, and treatment of hepatitis C: an update. American Association for the Study of Liver Diseases (AASLD) Practice Guidelines. Hepatology 2009;49(4):1335-74.

8. Centers for Disease Control and Prevention. Hepatitis C FAQs for health professionals, June 2009. Available from http://www.cdc.gov/hepatitis/HCV/HCVfaq.htm\# Accessed January 3, 2010.

9. Blackard JT, Shata MT, Shire NJ, Sherman KE. Acute hepatitis C virus infection: a chronic problem. Hepatology 2008;47(1):321-331.

10. Missiha SB, Ostrowski M, Heathcote EJ. Disease progression in chronic hepatitis C: modifiable and nonmodifiable factors. Gastroenterology 2008;134(6):1699-1714.

11. Amon JJ, Garfein RS, Ahdieh-Grant L, et al. Prevalence of hepatitis C virus infection among injection drug users in the United States, 1994-2004. Clin Infect Dis 2008;46(12):1852-58. 
12. U.S. Food and Drug Administration. FDA News Release: FDA approves rapid test for antibodies to hepatitis C virus, June 2010. Available from http://www.fda.gov/NewsEvents/Newsroom/PressAnnouncements/ucm217318.htm. Accessed June 28, 2010.

13. OraSure Technologies, Inc. Press Release: OraSure Technologies receives FDA approval for OraQuick® HCV Rapid Test, the first rapid HCV test approved for sale in the U.S., June 2010. Available from http://phx.corporate-

ir.net/phoenix.zhtml?c=99740\&p=RssLanding\&cat=news\&id=1441713 Accessed July 7, 2010 .

14. Nguyen MH, Keeffe EB. Prevalence and treatment of hepatitis C virus genotypes 4, 5, and 6. Clin Gastroenterol Hepatol. 2005;3(10 Suppl 2):S97-S101.

15. Varghese R, Al-Khaldi J, Asker H, Fadili AA, Al Ali J, Hassan FA. Treatment of chronic hepatitis $\mathrm{C}$ genotype 4 with peginterferon alpha-2a plus ribavirin. Hepatogastroenterology. 2009;56(89):218-22.

16. Kiser JJ. Trends in the treatment of chronic hepatitis $\mathrm{C}$ virus infection. Journal of Pharmacy Practice 2009;22(4):405-418.

17. U.S. Food and Drug Administration. Drugs@FDA. June 2010. Available from http://www.accessdata.fda.gov/scripts/cder/drugsatfda/index.cfm Accessed July 13, 2010.

18. Sandoz, Inc. Ribavirin package insert. Princeton, NJ; 2008.

19. Hoffman-La Roche Inc. Pegasys ${ }^{\circledR}$ (peginterferon alfa-2a) package insert. Nutley, NJ; 2010.

20. Schering Corporation. PegIntron ${ }^{\circledR}$ (peginterferon alfa-2b) package insert. Kenilworth, NJ; 2010 .

21. Fried MW, Shiffman ML, Reddy KR, et al. Peginterferon alfa-2a plus ribavirin for chronic hepatitis C virus infection. N Engl J Med 2002;347(13):975-82.

22. Manns MP, McHutchison JG, Gordon SC, et al. Peginterferon alfa-2b plus ribavirin compared with interferon alfa- $2 \mathrm{~b}$ plus ribavirin for initial treatment of chronic hepatitis: a randomised trial. Lancet 2001;358(9286):958-65. 
23. Di Bisceglie AM, Ghalib RH, Hamzeh FM, Rustgi VK. Early virologic response after peginterferon alpha-2a plus ribavirin or peginterferon alpha-2b plus ribavirin treatment in patients with chronic hepatitis C. J Viral Hepat 2007;14(10):721-9.

24. Escudero A, Rodríguez F, Serra MA, Del Olmo JA, Montes F, Rodrigo JM. Pegylated alphainterferon-2a plus ribavirin compared with pegylated alpha-interferon-2b plus ribavirin for initial treatment of chronic hepatitis $\mathrm{C}$ virus: prospective, non-randomized study. $\mathrm{J}$ Gastroenterol Hepatol 2008;23(6):861-6.

25. McHutchison JG, Lawitz EJ, Shiffman ML, Muir AJ, Galler GW, McCone J, et al; IDEAL Study Team. Peginterferon alfa-2b or alfa-2a with ribavirin for treatment of hepatitis $\mathrm{C}$ infection. N Engl J Med 2009;361(6):580-93.

26. Berg $\mathrm{T}$, von Wagner $\mathrm{M}$, Nasser $\mathrm{S}$, et al. Extended treatment duration for hepatitis $\mathrm{C}$ virus type 1: comparing 48 versus 72 weeks of peginterferon-alfa-2a plus ribavirin. Gastroenterology 2006;130(4):1086-97.

27. Pearlman BL, Ehleben C, Saifee S. Treatment extension to 72 weeks of peginterferon and ribavirin in hepatitis c genotype 1-infected slow responders. Hepatology 2007;46(6):1688-94.

28. Mangia A, Minerva N, Bacca D, et al. Individualized treatment duration for hepatitis C genotype 1 patients: a randomized controlled trial. Hepatology 2008;47(1):43-50.

29. Ferenci P, Laferl H, Scherzer TM, Gschwantler M, Maieron A, Brunner H, et al; Austrian Hepatitis Study Group. Peginterferon alfa-2a and ribavirin for 24 weeks in hepatitis $C$ type 1 and 4 patients with rapid virological response. Gastroenterology 2008;135(2):451-8.

30. Shiffman ML, Suter F, Bacon BR, Nelson D, Harley H, Solá R, et al; ACCELERATE Investigators. Peginterferon alfa-2a and ribavirin for 16 or 24 weeks in HCV genotype 2 or 3. N Engl J Med 2007;357(2):124-34.

31. Lagging M, Langeland N, Pedersen C, Färkkilä M, Buhl MR, Mørch K, et al; NORDynamIC Study Group. Randomized comparison of 12 or 24 weeks of peginterferon alpha-2a and ribavirin in chronic hepatitis C virus genotype 2/3 infection. Hepatology 2008;47(6):1837-45.

32. Dalgard O, Bjøro K, Ring-Larsen H, Bjornsson E, Holberg-Petersen M, Skovlund E, et al; North-C Group. Pegylated interferon alfa and ribavirin for 14 versus 24 weeks in patients with hepatitis $\mathrm{C}$ virus genotype 2 or 3 and rapid virological response. Hepatology 2008;47(1):35-42. 
33. Nguyen MH, Trinh HN, Garcia R, Nguyen G, Lam KD, Keeffe EB. Higher rate of sustained virologic response in chronic hepatitis $\mathrm{C}$ genotype 6 treated with 48 weeks versus 24 weeks of peginterferon plus ribavirin. Am J Gastroenterol 2008;103(5):1131-5.

34. Zeuzem S, Yoshida EM, Benhamou Y, et al. Albinterferon alfa-2b dosed every two or four weeks in interferon-naïve patients with genotype 1 chronic hepatitis $\mathrm{C}$. Hepatology 2008;48(2):407-17.

35. Bain VG, Kaita KD, Marotta $\mathrm{P}$, et al. Safety and antiviral activity of albinterferon alfa-2b dosed every four weeks in genotype $2 / 3$ chronic hepatitis $\mathrm{C}$ patients. Clin Gastroenterol Hepatol 2008;6(6):701-6.

36. Gish RG, Arora S, Reddy R, et al. Virological response and safety outcomes in therapy-naive patients treated for chronic hepatitis $\mathrm{C}$ with taribavirin or ribavirin in combination with pegylated interferon alfa-2a: a randomized, phase 2 study. J Hepatol 2007;47(1):51-9.

37. Marcellin P, Gish RG, Gitlin N, et al. Safety and efficacy of viramidine versus ribavirin in ViSER2: Randomized, double-blind study in therapy-naive hepatitis C patients. J Hepatol 2010;52:32-38.

38. McHutchison JG, Manns MP, Muir AJ, Terrault NA, Jacobson IM, Afdhal NH, et al; PROVE3 Study Team. Telaprevir for previously treated chronic HCV infection. N Engl J Med. 2010;362(14):1292-303.

39. Dalgard O, Bjøro K, Hellum KB, et al. Treatment with pegylated interferon and ribavirin in HCV infection with genotype 2 or 3 for 14 weeks: a pilot study. Hepatology 2004;40(6):1260-5.

40. Mangia A, Santoro R, Minerva N, et al. Peginterferon alfa-2b and ribavirin for 12 vs. 24 weeks in HCV genotype 2 or 3. N Engl J Med 2005;352(25):2609-17.

41. von Wagner M, Huber M, Berg T, et al. Peginterferon-alpha-2a (40KD) and ribavirin for 16 or 24 weeks in patients with genotype 2 or 3 chronic hepatitis C. Gastroenterology 2005;129(2):522-7.

42. Yu ML, Dai CY, Huang JF, et al. A randomised study of peginterferon and ribavirin for 16 versus 24 weeks in patients with genotype 2 chronic hepatitis C. Gut 2007;56(4):553-9.

43. Antaki N, Hermes A, Hadad M, et al. Efficacy of interferon plus ribavirin in the treatment of hepatitis C virus genotype 5. J Viral Hepat. 2008;15(5):383-6. 
44. Dieterich DT, Rizzetto M, Manns MP. Management of chronic hepatitis C patients who have relapsed or not responded to pegylated interferon alfa plus ribavirin. J Viral Hepat 2009;16(12):833-43.

45. Poynard T, Colombo M, Bruix J, Schiff E, Terg R, Flamm S, et al; Epic Study Group. Peginterferon alfa- $2 \mathrm{~b}$ and ribavirin: effective in patients with hepatitis $\mathrm{C}$ who failed interferon alfa/ribavirin therapy. Gastroenterology 2009;136(5):1618-28.

46. Jensen DM, Marcellin P, Freilich B, et al. Re-treatment of patients with chronic hepatitis C who do not respond to peginterferon-alpha2b: a randomized trial. Ann Intern Med 2009;150(8):528-40.

47. Soriano V, Peters MG, Zeuzem S. New therapies for hepatitis C virus infection. Clin Infect Dis 2009;48(3):313-320.

48. R\&D Insight. Available from http://bi.adisinsight.com/frames.aspx Accessed January 15, 2010.

49. Shields WW, Pockros PJ. Ribavirin analogs. Clin Liver Dis 2009;13(3):419-27.

50. Kearney KR, Thornton JJ, Navarro VJ. Taribavirin for the treatment of chronic hepatitis C. Expert Opin Pharmacother 2008;9(18):3243-9.

51. Berman K, Kwo PY. Boceprevir, an NS3 protease inhibitor of HCV. Clin Liver Dis 2009;13(3):429-39.

52. Lawitz E, Rodriguez-Torres M, Muir AJ, et al. Antiviral effects and safety of telaprevir, peginterferon alfa-2a, and ribavirin for 28 days in hepatitis $\mathrm{C}$ patients. J Hepatol 2008;49(2):163-9.

53. Forestier N, Reesink HW, Weegink CJ, et al. Antiviral activity of telaprevir (VX-950) and peginterferon alfa-2a in patients with hepatitis C. Hepatology 2007;46(3):640-648.

54. Sarrazin C, Rouzier R, Wagner F, et al. SCH 503034, a novel hepatitis C virus protease inhibitor, plus pegylated interferon alpha- $2 \mathrm{~b}$ for genotype 1 nonresponders. Gastroenterology. 2007;132(4):1270-8. 
55. McHutchison JG, Everson GT, Gordon SC, Jacobson IM, Sulkowski M, Kauffman R, et al; PROVE1 Study Team. Telaprevir with peginterferon and ribavirin for chronic HCV genotype 1 infection. N Engl J Med 2009;360(18):1827-38.

56. Hézode C, Forestier N, Dusheiko G, Ferenci P, Pol S, Goeser T, et al; PROVE2 Study Team. Telaprevir and peginterferon with or without ribavirin for chronic HCV infection. N Engl J Med 2009;360(18):1839-50.

57. Kim AI, Dorn A, Bouajram R, Saab S. The treatment of chronic hepatitis C in HIV-infected patients: a meta-analysis. HIV Med 2007;8(5):312-21.

58. Dionne-Odom J, Osborn MK, Radziewicz H, Grakoui A, Workowski K. Acute hepatitis C and HIV coinfection. Lancet Infect Dis 2009;9(12):775-83.

59. Berenguer J, Alvarez-Pellicer J, Martín PM, López-Aldeguer J, Von-Wichmann MA, Quereda C, et al; GESIDA3603/5607 Study Group. Sustained virological response to interferon plus ribavirin reduces liver-related complications and mortality in patients coinfected with human immunodeficiency virus and hepatitis $\mathrm{C}$ virus. Hepatology 2009;50(2):407-13.

60. Gluud LL, Marchesini E, Iorio A. Peginterferon plus ribavirin for chronic hepatitis C in patients with human immunodeficiency virus. Am J Gastroenterol 2009;104(9):2335-41.

61. Hughes CA, Shafran SD. Treatment of hepatitis C in HIV-coinfected patients. Ann Pharmacother. 2006;40(3):479-489.

62. Pol S, Soriano V. Management of chronic hepatitis C virus infection in HIV-infected patients. Clin Infect Dis 2008;47(1):94-101.

63. Berenguer M. Treatment of chronic hepatitis $\mathrm{C}$ in hemodialysis patients. Hepatology 2008;48(5):1690-99.

64. Girndt M. Viral hepatitis in elderly hemodialysis patients: current prevention and management strategies. Drugs Aging 2008;25(10):823-40.

65. Gordon CE, Uhlig K, Lau J, Schmid CH, Levey AS, Wong JB. Interferon for hepatitis C virus in hemodialysis--an individual patient meta-analysis of factors associated with sustained virological response. Clin J Am Soc Nephrol 2009;4(9):1449-58. 
66. Hakim W, Sheikh S, Inayat I, et al. HCV response in patients with end stage renal disease treated with combination pegylated interferon alpha-2a and ribavirin. J Clin Gastroenterol 2009;43(5):477-81.

67. Sylvestre DL. Approaching treatment for hepatitis C virus infection in substance users. Clin Infect Dis 2005;41(suppl 1):S79-82.

68. Bruggmann P, Falcato L, Dober S, Helbling B, Keiser O, Negro F, et al; Swiss Hepatitis C Cohort Study. Active intravenous drug use during chronic hepatitis $\mathrm{C}$ therapy does not reduce sustained virological response rates in adherent patients. J Viral Hepat 2008;15(10):747-52.

69. Sulkowski M, Wright T, Rossi S, et al. Peginterferon alfa-2a does not alter the pharmacokinetics of methadone in patients with chronic hepatitis $\mathrm{C}$ undergoing methadone maintenance therapy. Clin Pharmacol Ther 2005;77(3):214-24.

70. De Rosa FG, Bargiacchi O, Audagnotto S, et al. Twelve-week treatment of acute hepatitis C virus with pegylated interferon-alpha- $2 \mathrm{~b}$ in injection drug users. Clin Infect Dis 2007;45(5):583-588.

71. American College of Obstetricians and Gynecologists (ACOG). Viral hepatitis in pregnancy. Washington (DC): American College of Obstetricians and Gynecologists (ACOG); 2007 Oct. 15 p. (ACOG practice bulletin; no. 86).

72. Su GL. Hepatitis C in pregnancy. Curr Gastroenterol Rep. 2005;7(1):45-9.

73. Roberts SS, Miller RK, Jones JK, et al. The Ribavirin Pregnancy Registry: Findings after 5 years of enrollment, 2003-2009. Birth Defects Res A Clin Mol Teratol. 2010 Jun 17. [Epub ahead of print]

74. Fiore S, Savasi V. Treatment of viral hepatitis in pregnancy. Expert Opin Pharmacother. 2009;10(17):2801-9.

75. Davison SM, Kelly DA. Management strategies for hepatitis $C$ virus infection in children. Pediatr Drugs 2008;10(6):357-65.

76. Wirth S, Pieper-Boustani H, Lang T, et al. Peginterferon alfa-2b plus ribavirin treatment in children and adolescents with chronic hepatitis C. Hepatology. 2005;41(5):1013-8. 
77. Jara P, Hierro L, de la Vega A, et al. Efficacy and safety of peginterferon-alpha2b and ribavirin combination therapy in children with chronic hepatitis $\mathrm{C}$ infection. Pediatr Infect Dis J. 2008;27(2):142-8. 


\section{FOOTNOTES}

Table 1. Selected AASLD Guideline Recommendations for Management of Hepatitis $\mathrm{C}^{7}$

AASLD $=$ American Association for the Study of Liver Diseases.

${ }^{\mathrm{a}}$ The AASLD classifications of recommendations are as follows:

The AASLD classifications of recommendations are as follows: Class I = conditions for which there is evidence and/or general agreement that a given diagnostic evaluation procedure or treatment is beneficial, useful, and effective; II = conditions for which there is conflicting evidence and/or a divergence of opinion about the usefulness/efficacy of a diagnostic evaluation, procedure or treatment; IIa = weight of evidence/opinion is in favor of usefulness/efficacy; IIb = usefulness/efficacy is less well established by evidence/opinion; III = conditions for which there is evidence and/or general agreement that a diagnostic evaluation, procedure/treatment is not useful/effective and in some cases may be harmful.

The AASLD levels of evidence are as follows: $\mathrm{A}=$ data derived from multiple randomized clinical trials or meta-analyses; $\mathrm{B}=$ data derived from a single randomized trial, or non-randomized studies; $\mathrm{C}=$ only consensus opinion of experts, case studies, or standard-of-care.

Table 2. HCV Risk Factors ${ }^{1-3,7,9-10}$

Table 3. Diagnosis of $\mathrm{HCV}^{3,7}$

Table 4. Definitions of Treatment Responses in $\mathrm{HCV}^{7}$

Table 5. Clinical Trials of Therapies for the Treatment of Hepatitis $C^{23-33}$

$\mathrm{RBV}=$ ribavirin

Peg-IFN alfa-2a = peginterferon alfa-2a

Peg-IFN alfa- $2 \mathrm{~b}=$ peginterferon alfa- $2 \mathrm{~b}$

Peg-IFN $=$ peginterferon

${ }^{\mathrm{a}}$ Complete treatment regimens with dosing are provided in text

${ }^{\mathrm{b}}$ Percentages were rounded to the nearest whole number

${ }^{\mathrm{c}}$ Slow Responders: HCV RNA positive at 12 weeks

${ }^{\mathrm{d}}$ Slow Responders: 2-log reduction in HCV RNA and undetectable levels at week 24 
${ }^{\mathrm{e}}$ Treatment duration was 24 weeks

${ }^{\mathrm{f}}$ Treatment duration was 72 weeks

${ }^{\mathrm{g}}$ Overall RVR occurred in $302 / 428$ patients prior to randomization

Table 6. Clinical Trials of Alternative and Investigational Therapies for the Treatment of Hepatitis $\mathrm{C}^{34-38}$

$\mathrm{RBV}=$ ribavirin

Peg-IFN alfa-2a = peginterferon alfa-2a

Peg-IFN alfa-2b = peginterferon alfa-2b

Alb-IFN alfa-2b = albinterferon alfa-2b

Ta-RBV = taribavirin

${ }^{\mathrm{a}}$ Complete treatment regimens with dosing are provided in text

${ }^{\mathrm{b}}$ Percentages were rounded to the nearest whole number

${ }^{\mathrm{c}}$ Dependent upon HCV genotype (genotype 2/3: duration 24 weeks; non 2/3: duration 48 weeks)

${ }^{\mathrm{d}}$ Majority of patients discontinued as a result of meeting a stopping rule, including virologic breakthrough, nonresponse at week 4,12 or 24 


\section{TABLES}

Table 1. Selected AASLD Guideline Recommendations for Management of Hepatitis $\mathrm{C}^{7}$

\section{Intervention}

Treatment decisions should be individualized based on the severity of liver disease, the potential for serious side

effects, the likelihood of treatment response, the presence of comorbid conditions, and willingness to undergo treatment.

The optimal therapy for chronic $\mathrm{HCV}$ infection is the combination of peginterferon alfa and ribavirin.

HCV RNA should be tested at the initiation of or shortly before treatment and at week 12 of therapy.

\section{Genotypes 1 and 4 HCV Infection}

Treatment with peginterferon plus ribavirin should be planned for 48 weeks; the dose for peginterferon alfa- $2 \mathrm{a}$ is

$180 \mu \mathrm{g}$ subcutaneously per week together with ribavirin using doses of $1000 \mathrm{mg}$ for those $<75 \mathrm{~kg}$ in weight and $1200 \mathrm{mg}$ for those $>75 \mathrm{~kg}$; the dose for peginterferon alfa- $2 \mathrm{~b}$ is $1.5 \mu \mathrm{g} / \mathrm{kg}$ subcutaneously per week together with ribavirin using doses of $800 \mathrm{mg}$ for those weighing $<65 \mathrm{~kg} ; 1000 \mathrm{mg}$ for those weighing $>65 \mathrm{~kg}$ to $85 \mathrm{~kg}, 1200 \mathrm{mg}$ for $>85 \mathrm{~kg}$ to $105 \mathrm{~kg}$, and $1400 \mathrm{mg}$ for $>105 \mathrm{~kg}$.

Treatment may be discontinued in patients who do not achieve an EVR.

Patients who do not achieve a complete EVR should be re-tested at week 24, and if HCV RNA remains positive,
AASLD Class, Level of Evidence ${ }^{a}$

IIa, C

I, A 
Patients with genotype 1 infection whose treatment continues through 48 to 72 weeks and whose measurement of HCV is negative at the end of treatment should be retested for HCV RNA 24 weeks later to evaluate for SVR.

\section{Genotype 2 or Genotype 3 HCV Infection}

Treatment with peginterferon plus ribavirin should be administered for 24 weeks, using a ribavirin dose of $800 \mathrm{mg}$.

I, A

\section{Genotype 2 or Genotype 3 HCV Infection}

Patients whose treatment continues through 24 weeks and whose measurement of HCV RNA is negative should be retested for HCV RNA 24 weeks later to evaluate for SVR.

Retreatment with peginterferon plus ribavirin can be considered for non-responders or relapsers who have previously been treated with non-pegylated interferon with or without ribavirin, or with peginterferon monotherapy, particularly if they have bridging fibrosis or cirrhosis.

Retreatment with peginterferon plus ribavirin in patients who did not achieve SVR after a prior full course of peginterferon plus ribavirin is not recommended, even if a different type of peginterferon is administered.

For relapsers: III, C;

For non-responders: III, B

Initial treatment of hepatitis $\mathrm{C}$ in most $\mathrm{HIV}$-infected patients should be peginterferon plus ribavirin for 48 weeks at doses recommended for HCV mono-infected patients. 
Chronic Hepatitis C\& Current Therapies 37

Children aged 2-17 years who are infected with HCV should be considered appropriate candidates for treatment using

the same criteria as that used for adults.

IIa, B 
Table 2. HCV Risk Factors ${ }^{1-3,7,9-10}$

\section{Risk Factor}

Injection drug use

Blood or blood component prior to 1992

Healthcare exposure

Patients who have ever been on chronic hemodialysis Higher prevalence of HCV infection

Patients with HIV

Children of HCV-infected mothers

Current partners of $\mathrm{HCV}$-infected persons

Persons with multiple sexual partners

\section{Explanation}

Most common route of exposure

Routine blood screening implemented in 1992

Following needle stick injury or mucosal exposure of HCV positive blood

\section{Recommendation}

Screen

Screen

Screen

Screen

Screen

Screen

Screen for reassurance

Safe sexual practices 
Table 3 . Diagnosis of $\mathrm{HCV}^{3,7}$

\section{Anti-RNA (EIA) HCV RNA}

Positive

Negative

Positive

Negative

Negative

\section{Interpretation}

Acute or chronic infection

Acute infection with low level viremia or resolution of infection

Possible false-positive HCV RNA, acute infection or inadequate immune response

Absence of infection

\section{Follow-up}

Assess for therapy

Consider repeat testing in 4 to 6

months; evaluate signs/symptoms

Consider repeat testing in 4 to 6

months

Assess for at-risk behaviors and

development of signs/symptoms 


\author{
Table 4. Definitions of Treatment Responses in $\mathrm{HCV}^{7}$ \\ Response \\ Rapid virologic response (RVR) \\ Early virologic response (EVR) \\ End-of-treatment response (ETR) \\ Sustained virologic response (SVR) \\ Breakthrough \\ Relapse \\ Nonresponder \\ Partial responder

\section{Definition} \\ Undetectable HCV RNA at week 4 of therapy \\ At least a 2-log reduction in HCV RNA by 12 weeks of \\ therapy \\ No detectable HCV RNA at the end of therapy \\ No detectable HCV RNA at the conclusion of treatment and \\ 24 weeks after discontinuation of therapy \\ Reappearance of HCV RNA while still receiving therapy \\ Reappearance of HCV RNA after discontinuation of therapy \\ Failure to achieve undetectable HCV RNA after 24 weeks \\ of therapy \\ At least a 2-log reduction in HCV RNA but never reaches \\ undetectable HCV RNA
}


Table 5. Clinical Trials of Therapies for the Treatment of Hepatitis $\mathrm{C}^{23-33}$

\section{Author Genotype Study Treatment ${ }^{\mathrm{a}}$}

Comparative Efficacy of Pegylated Interferons

Di Bisceglie et al. ${ }^{23}$

Peg-IFN alfa-2a + RBV

vs. Peg-IFN alfa- $2 \mathrm{~b}+\mathrm{RBV}$

Escudero et al. ${ }^{24} \quad 1-4 \quad$ Peg-IFN alfa-2a + RBV

vs. Peg-IFN alfa- $2 b+$ RBV

McHutchison et al. ${ }^{25} 1$

3070

Low-dose Peg-IFN alfa- $2 b+$ RBV

Standard Peg-IFN alfa-2a

Duration of Therapy According to Genotype

Berg et al. ${ }^{26} \quad 1 \quad$ Peg-IFN alfa-2a + RBV

455

48

72

48

24

62

38

41

53

$29 / 24$

$17^{\mathrm{c}}$

$54 \quad 21 / 41$

$29^{\mathrm{c}}$

Pearlman et al. ${ }^{27} \quad 1 \quad$ Peg-IFN alfa-2b + RBV

101

24

$18^{\mathrm{d}} \quad 59 / 14$

48

$38^{\mathrm{d}} \quad 20 / 15$ 
Chronic Hepatitis C\& Current Therapies 42

\begin{tabular}{|c|c|c|c|c|c|c|c|}
\hline Mangia et al. ${ }^{28}$ & 1 & Peg-IFN alfa-2a or & 696 & 24 & $\underline{\text { Standar }}$ & & Standar \\
\hline & & Peg-IFN alfa- $2 b+$ RBV & & 48 & $\underline{\text { Variabl }}$ & (R): & Variabl \\
\hline & & & & 72 & Week 4 & $37 \mathrm{vs}$ & \\
\hline & & & & & Week 8 & $70 \mathrm{vs}$ & \\
\hline & & & & & Week 1 & 38 & $63^{f}$ \\
\hline Ferenci et al. ${ }^{29}$ & $1 / 4$ & Peg-IFN alfa-2a + RBV & 516 & 24 & 29 & 77 & $11 / 1$ \\
\hline Shiffman et al. ${ }^{30}$ & $2 / 3$ & Peg-IFN alfa-2a + RBV & 1469 & 16 & $67 / 89$ & 65 & $31 / 4$ \\
\hline & & & & 24 & $64 / 89$ & 76 & $18 / 5$ \\
\hline Lagging et al. ${ }^{31}$ & $2 / 3$ & Peg-IFN alfa-2a + RBV & 382 & 12 & & 59 & $33 / 1$ \\
\hline & & & & 24 & & 78 & $12 / 10$ \\
\hline Dalgard et al. ${ }^{32}$ & $2 / 3$ & Peg-IFN alfa- $2 b+R B V$ & 428 & 14 & $71^{g}$ & 81 & $11 / 6$ \\
\hline & & & & 24 & & 91 & $5 / 21$ \\
\hline Nguyen et al. ${ }^{33}$ & 6 & Peg-IFN + RBV & 35 & 24 & & 39 & \\
\hline & & & & 48 & & 75 & \\
\hline
\end{tabular}


Chronic Hepatitis $C$ \& Current Therapies 43

Table 6. Clinical Trials of Alternative and Investigational Therapies for the Treatment of Hepatitis $\mathrm{C}^{34-38}$

Author Population/Genotype Study Treatment

Albinterferon

Zeuzem et al. ${ }^{34} \quad$ Treatment naïve/1

Bain et al. ${ }^{35}$

Treatment naïve $/ 2 / 3$

Alb-IFN alfa-2b Q 2 wks vs.

43

Alb-IFN alfa-2b Q 4 wks

Taribavirin

Gish et al. ${ }^{36} \quad$ Treatment naïve

Ta-RBV 1200 mg + Peg-IFN alfa-2a vs. 18

Ta-RBV 800 mg + Peg-IFN alfa-2a vs.

Ta-RBV 1600 mg + Peg-IFN alfa-2a vs

$\mathrm{RBV}+$ Peg-IFN alfa-2a

Ta-RBV + Peg-IFN alfa-2a vs.

RBV + Peg-IFN alfa-2a

Protease Inhibitors

McHutchison et al. ${ }^{38}$ Previously treated/1
T12PR24 ${ }^{\mathrm{a}}$
Marcellin et al. ${ }^{37} \quad$ Treatment naïve
No. of Patients Duration (wks) SVR ${ }^{\mathrm{b}}$ Relapse/Discontinuation ${ }^{\mathrm{b}}$

458

$59 \quad 29 / 19$

$56 \quad 31 / 29$

$51 \quad 28 / 17$

$58 \quad 29 / 13$

$62 \quad 28 / 38$

$77 \quad 19 / 14$

962

$24-48^{c}$

$40 \quad 35 / 26$

$55 \quad 18 / 26$

$\begin{array}{lll}24-48^{\mathrm{c}} & 37 & 42 / 25 \\ & 23 & 64 / 24 \\ & 29 & 57 / 30 \\ & 44 & 41 / 21 \\ 24-48^{\mathrm{c}} & 40 & 35 / 26 \\ & 55 & 18 / 26\end{array}$

Varied

$5130 / 25^{\mathrm{d}}$ 
Chronic Hepatitis C \& Current Therapies 44

T24PR48

$\mathrm{T} 24 \mathrm{P} 24$

PR48
$53 \quad 13 / 51^{\mathrm{d}}$

$2453 / 48^{\mathrm{d}}$

$1453 / 68^{\mathrm{d}}$ 


\section{FIGURE LEGENDS}

Figure 1. U.S. Incidence of Acute Hepatitis C, 1980-2007 